\title{
Ameliorative Effect Of Zinc Oxide Nanoparticles Against Dermal Toxicity Induced By Lead Oxide In Rats
}

\author{
AA Khalaf (D' \\ Eman I Hassanen ${ }^{2}$ \\ Rehab A Azouz (D) ${ }^{1}$ \\ Amr R Zaki ${ }^{3}$ \\ Marwa A Ibrahim (D) ${ }^{4}$ \\ Khaled Y Farroh ${ }^{5}$ \\ Mona K Galal ${ }^{4}$ \\ 'Department of Toxicology \& Forensic \\ Medicine, Faculty of Veterinary Medicine, \\ Cairo University, Giza, Egypt; \\ ${ }^{2}$ Department of Pathology, Faculty of \\ Veterinary Medicine, Cairo University, \\ Giza, Egypt; ${ }^{3}$ Department of Forensic \\ Medicine and Clinical Toxicology, Faculty \\ of Medicine, Beni-Suef University, Beni- \\ Suef, Egypt; ${ }^{4}$ Department of \\ Biochemistry, Faculty of Veterinary \\ Medicine, Cairo University, Giza, Egypt; \\ ${ }^{5}$ Nanotechnology \& Advanced Materials \\ Central Lab, Agricultural Research \\ Center, Giza, Egypt
}

This article was published in the following Dove Press journal: International Journal of Nanomedicine

Background: Recently, several studies demonstrate the possible role of zinc oxide $(\mathrm{ZnO})$ in the protection of several skin diseases, but less is known about the role of $\mathrm{ZnO}$ nanoparticles in the inflammatory skin disease. So, this study was designed to confirm the pivotal role of the nano zinc oxide cream in the alleviation of lead oxide $(\mathrm{PbO})$ induced-allergic dermatitis in rats.

Materials and methods: Two concentrations (1\% and $6 \%)$ of $\mathrm{ZnONPs}$ creams were prepared and characterized prior to being used in the study. A total number of 30 male Wistar rats were randomly divided into six groups. Group 1 (negative control), groups $2 \& 3$ (either $1 \%$ or $6 \% \mathrm{ZnONPs}$ control groups), group $4(\mathrm{PbO})$, groups $5 \& 6$ (co-treatment of each $\mathrm{ZnONPs}$ concentration $+\mathrm{PbO}$ ). All rats in different groups were observed daily to determine the severity of dermal gross lesions. Histopathological studies, mRNA analysis, and oxidative stress evaluations were performed on the affected skin tissue. Immunohistochemical studies were performed to evaluate the expression of cluster of differentiation CD4, CD8 and intercellular adhesion molecules ICAM-1 in different groups.

Results: $\mathrm{PbO}$ caused extensive skin oxidative damage manifested by a significant increase in MDA level with a decrease in GSH content and CAT activity. The results of histopathological and immunohistochemical examinations revealed that topical application of $\mathrm{PbO}$ for 14 days led to severe allergic dermatitis with remarkable elevations in the number of CD4+ T-helper, CD8+ T-cytotoxic lymphocytes, and ICAM-1 expression. On the other hand, noticeable improvements were recorded in all the previous toxicopathological parameters among the groups treated by either $1 \%$ or $6 \% \mathrm{ZnO}-\mathrm{NPs}$ cream. However, the best results were observed in the group treated with $1 \% \mathrm{ZnO}-\mathrm{NPs}$ cream.

Conclusion: Our findings suggest that $1 \%$ of $\mathrm{ZnO}-\mathrm{NPs}$ cream is safe when applied topically on the inflamed skin. Moreover, it had anti-inflammatory and antioxidant effects so that, it is recommended to use the $1 \% \mathrm{ZnO}-\mathrm{NPs}$ cream to avert the dermal toxicity-induced by $\mathrm{PbO}$.

Keywords: skin, nanoparticles, histopathology, immunohistochemistry, oxidative stress, collagen gene

\section{Introduction}

Lead is considered one of the most global, cumulative occupational and environmental pollutants that affect all the biological systems through exposure to air, water, and food sources. ${ }^{1,2}$ The exposure to lead initials severe clinical changes through systemic and dermal toxicity. ${ }^{3}$ Lead can cause toxic health effects through inhalation, ingestion, and skin contact. ${ }^{4}$ Skin contamination by dust containing lead and other
Correspondence: Marwa A Ibrahim Department of Biochemistry, Faculty of Veterinary Medicine, Cairo University, Giza 1221 I, Egypt

Tel +2021001904594

Fax +2023572540

Email marwa199@gmail.com 
toxic metals is not generally regarded by researches as the hazardous risk through dermal penetration. Little experimental studies were conducted on the dermal toxic effect of lead paints on workers or experimental animals. ${ }^{5}$ Lead is attributed to the induction of oxidative stress by elevation of reactive oxygen species (ROS) such as lipid peroxide, hydroxyl radical and hydrogen peroxide and superoxide radical. ${ }^{6}$ However, exaggerated ROS production happens in various pathologic things as hematopoietic stem cell apoptosis, ${ }^{7}$ cell membrane injury, ${ }^{8}$ interferes with DNA transcription, enzymes that facilitate within the synthesis of vitamin D, and enzymes that maintain the integrity of the cell membrane. ${ }^{9}$ Lead interferes with the metabolism of bones and teeth and alters the permeability of blood vessels and collagen synthesis. ${ }^{10}$ Collagen is the most extensive protein within the extracellular matrix of skin that imparts the dermis tensile properties. Collagen is responsible for structure, stability, and strength, especially within the dermal layers. ${ }^{11}$ About one-half of the total human body collagen is present in the skin, being mostly collagen type I. ${ }^{12}$ The degradation of type I collagen is initiated by matrix metalloproteinases-1 (MMP-1) and enhanced by over ROS production. ${ }^{13}$ Several researchers reported that high concentrations of lead acetate or lead oxide delayed the synthesis of collagen fiber. ${ }^{14,15}$

Dermal toxicity induced by topical application of lead oxide thought-about as a sort of T-cell mediates delayed- hypersensitivity reactions in the form of allergic contact dermatitis. ${ }^{16}$ Pathologic process of allergic dermatitis (AD) is divided into a pair of phases: sensitization, and elicitation phases. Through-out the sensitization phase, the epicutaneously applied hapten is obsessed and processed by epidermal Langerhans cells, and presented to naive $\mathrm{T}$ cells within the draining lymph nodes then, convert to hapten-specific $\mathrm{T}$ cells. During the elicitation phase, reapplication of the same hapten ends up in the achievement of hapten-specific $T$ cells that react to the hapten given by Langerhans cells, release cytokines and chemokines which attract different inflammatory cells chiefly mast cells and eosinophils. ${ }^{17-19} \mathrm{~T}$ cells either $\mathrm{T}$ helper cells or T-cytotoxic cells are thought to play a significant role within the pathologic process of AD. ${ }^{20-22}$ A typical feature of $\mathrm{AD}$ is that the category of the switch from Th2 kind immunity within the acute phase toward Th1 throughout the chronic phase. ${ }^{23}$ In the acute phase, infiltration of $\mathrm{T}$ cells and eosinophils into the dermis may be ascertained in parallel with the release of Th2 kind cytokines IL-4 and IL-13. ${ }^{24,25}$

Nanotechnology has shown a tremendous and rapid growth related to their broad applications in many fields, like electronics, cosmetics, food industry, and medicine. Metal nanoparticles (NPs) and their oxides have a considerable number of present and future applications in the medical and industrial fields. The smaller size and unique
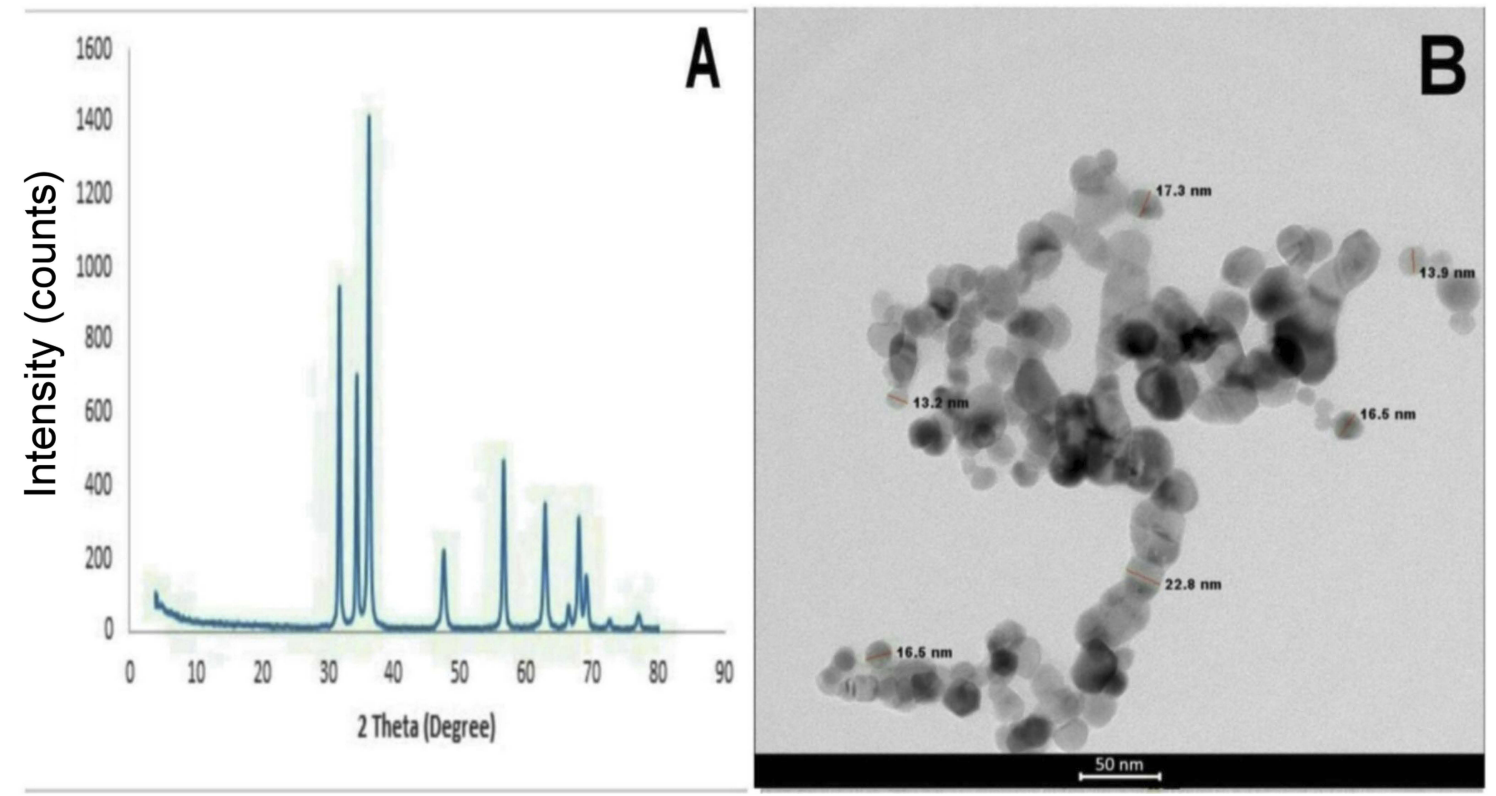

Figure I (A) X-ray powder diffraction (XRD) pattern of the synthesized ZnO nanoparticles. (B) high-resolution transmission electron microscopic (HRTEM) images of zinc oxide nanoparticles. 
properties of NPs have substantially improved their application. ${ }^{26} \mathrm{ZnO}$ is well-known and widely used metal oxides in several numerous products like paints, coatings and cosmetics product like sunscreens thanks to their anti-inflammatory, antioxidant, antimicrobial or UV ray protecting properties. ${ }^{27,28}$ The raised utilization of this material stems from the issue related to the bulk-sized inorganic ingredients that were employed in the older generations of the product. The poor dispersion quality, opaqueness and comedogenic properties of non-nanoscale $\mathrm{ZnO}$ have inspired makers to boost their productivity by reducing the dimension of the particles. ${ }^{29}$ Nowadays, sunscreens are one in all few nanomaterial-containing products to which individuals are intentionally exposed. ${ }^{30}$

Topical exposure to various nanoparticles, particularly $\mathrm{ZnO}-\mathrm{NPs}$, and therefore the penetration of them into the contact skin has been antecedently investigated; but, the results of the studies are somewhat contentious. What is more, there is a scarcity of information regarding the effect of $\mathrm{ZnO}-\mathrm{NPs}$ on injured or inflamed skin. Once taking under consideration the high prevalence of dermal toxicity especially allergic dermatitis, there's some concern regarding whether or not concentration-dependent ZnO-NPs will cause hazard once applied repeatedly onto the injured and inflamed skin. The aim of the current study was to analyze the protecting effects of local application of two different concentrations of nano- $\mathrm{ZnO}$ cream $(1 \%$ and $6 \%)$ against lead-induced allergic dermatitis in a rat model.

\section{Materials And Methods Chemicals And Reagents}

Lead paint (red lead) used as a source of lead oxide and was purchased from the paint market. Zinc sulfate heptahydrate (zinc precursors), sodium hydroxide pellets and other chemical were purchased from Sigma-Aldrich, St. Louis, MO, USA, Chemical Company. CD4 primary antibody, CD8 primary antibody, ICAM-1 primary antibody as well as peroxidase block and DAP kit purchased from Abcam, Ltd., USA.

\section{Preparation Of Nanosized Zinc Oxide Cream}

Zinc oxide nanoparticles ( $\mathrm{ZnO}-\mathrm{NPs}$ ) were synthesized by the precipitation method. ${ }^{31}$ In the typical procedure, $5.4875 \mathrm{~g}$ of zinc sulfate heptahydrate was dissolved in 50 $\mathrm{mL}$ of deionized water (Milli-Q, Millipore, USA) and then, $2 \mathrm{~g}$ of sodium hydroxide in $50 \mathrm{~mL}$ of deionized water was added dropwise under magnetic stirring for $30 \mathrm{~min}$. The precipitates were filtered and washed by pure water several times. Then, obtained precipitates were dried at $60^{\circ} \mathrm{C}$ for 24 $\mathrm{h}$ and claimed at $400^{\circ} \mathrm{C}$ for $2 \mathrm{~h}$. The cream base was prepared according to the previous study ${ }^{32}$ and was used as a vehicle for $\mathrm{ZnO}-\mathrm{NPs}$. Briefly, Stearic acid (25\%), cetyl alcohol $(2 \%)$, and glycerol $(12 \%)$ were taken into a porcelain dish and melted at $70^{\circ} \mathrm{C}$ (oil phase). The aqueous phases of potassium hydroxide (2\%), propylparaben $(0.05 \%)$, methylparaben $(0.1 \%)$, and water $(58.85 \%)$ were taken into another porcelain dish and heated at $70^{\circ} \mathrm{C}$. The aqueous phase was added to the oil phase with continuous stirring at $70^{\circ} \mathrm{C}$ till complete saponification. The prepared $\mathrm{ZnO}$ nanocrystals were added to the prepared cream by mixing in a morter at a concentration of $1 \%$ and $6 \%$.

\section{Characterization Of Nanoparticles}

The crystalline and phase structure of the synthesized $\mathrm{ZnO}$ was studied by an X-ray diffractometer (XRD, X'Pert Pro, PanAlytical, Netherlands). The morphology and size were determined by the transmission electron microscopy (TEM, Tecnai G20, FEI, Netherlands). All the Preparation and characterization processes were conducted at Nanotechnology and Advanced Materials Central Lab (NAMCL), Agricultural Research Center, Egypt.

\section{Animals And Experimental Design}

All procedures were conducted in accordance with the guidelines contained in the guide for the care and use of laboratory animals. The protocol was approved by the Veterinary Institutional Animal Care and Use Committee at Cairo University (VetCU0722019061), Cairo, Egypt. Thirty male albino Wistar rats weighing 170-200gm were obtained from the department of veterinary hygiene and management's animal house, faculty of veterinary medicine, Cairo University. All animals were housed in plastic cages ( 5 rats/cage) in a well-ventilated environment and received a daily illumination of $12 \mathrm{hrs}$ of light. They were fed on dry commercial standard pellets and gain access to tap water ad-libitum throughout the experimental period. They were acclimatized to the environment for 2 weeks prior to the onset of the experiment to ensure their healthy state.

Rats were randomly assigned into six groups $(n=5)$ as in Table 1. Group (1) was kept as negative control and applied only sterile normal saline topical on the skin every alternate day for 14 days. Groups (2\&3) received $1 \%$ and $6 \%$ nanosized zinc oxide ( $\mathrm{ZnO}-\mathrm{NPs}$ ) cream locally on the skin after hair removal, daily for 14 days. Group (4) 
Table I Experimental Design

\begin{tabular}{|l|l|l|l|}
\hline Groups & Drugs & Route/day & Durations \\
\hline $\mathrm{I}$ & Normal saline & Dressing & $14 \mathrm{~d}$ \\
2 & $1 \% \mathrm{ZnO}$ NPs cream & Topical & $14 \mathrm{~d}$ \\
3 & $6 \% \mathrm{ZnO}$ NPs cream & Topical & $14 \mathrm{~d}$ \\
4 & $10 \% \mathrm{PbO}$ & Dressing & $14 \mathrm{~d}$ \\
5 & $1 \%$ ZnO NPs cream $+10 \%$ & Topical & $14 \mathrm{~d}$ \\
& $\mathrm{PbO}$ & Dressing & $14 \mathrm{~d}$ \\
6 & $6 \%$ ZnO NPs cream $+10 \%$ & Topical & $14 \mathrm{~d}$ \\
& $\mathrm{PbO}$ & Dressing & $14 \mathrm{~d}$ \\
\hline
\end{tabular}

Notes: saline, ZnONPs and $\mathrm{PbO}$ were applied daily on the skin of rats in different groups

Abbreviations: $\mathrm{ZnO}-\mathrm{NPs}$, zinc oxide nanoparticles; $\mathrm{PbO}$, lead oxide.

received $10 \%$ red lead or lead oxide $(\mathrm{PbO})$ topically on the skin after hair removal, daily for 14 days. Groups (5\&6) were given both $\mathrm{ZnO}-\mathrm{NPs}$ cream and $\mathrm{PbO}$ topically on the skin. Two different concentrations of $\mathrm{ZnO}$-NPs were selected according to a previous study. ${ }^{33}$ The cream base control group was not incorporated in the experimental design because the assessment of the irritation induced by the cream base on the intact skin was previously done and showed neither erythema nor edema, indicating that this cream base not irritant to the skin of animals. ${ }^{32}$

\section{Gross Evaluation Of Dermatitis Severity}

The degree of severity of dermatitis was determined grossly based on the presence of erythema, edema, ulcer/erosion, and dryness/scaling/crusting then evaluated according to the severity index scoring system described by Young et al, ${ }^{34}$ Skin lesions on the back (area of the topical application of the used materials) were scored based on the presence of clinical symptoms as follows: none $=0$, mild $=1$, moderate $=2$, and severe $=3$.

\section{Histopathological Studies}

$10 \%$ neutral buffered formalin-fixed paraffin-embedded skin tissue samples were sliced into $4.5 \mu \mathrm{m}$ sections. The sections were stained with H\&E for histopathological examination. ${ }^{35}$ Toluidine blue and Congo red stain were used as needed for determination of mast cells and eosinophils respectively.

Skin tissue sections were assessed for epidermal edema (spongiosis and vacuolar degenerations), epidermal hyperplasia, dermal edema, and inflammation using the following scoring system: none (-), mild $(+)$, moderate $(++)$, severe $(+++)$ skin tissue damage. ${ }^{36}$
Morphometric studies applied to measure the full skin thickness in different groups, as well as the number of mast cells (toluidine blue positive cells) and eosinophils (Congo red positive cells) per high power field, were calculated. Cells were visually counted in a random fashion throughout the whole skin tissue sections using $400 \mathrm{X}$ magnification. A total of 10 high power fields were used from each skin tissue sections (5 sections representing 5 rats per group).

\section{Immunohistochemical Studies}

The deparaffinized and dehydrated slides were quenched in 3\% hydrogen peroxide to neutralize endogenous peroxidase activity, then washed in PBS-T, and blocked in $1 \%$ bovine serum albumin. Slides were incubated with primary antibody against CD4 (cluster of differentiation) or CD8 or ICAM-1 (intercellular adhesion molecule-1)at 1:400 dilutions overnight at $4^{\circ} \mathrm{C}$. The slides were washed and incubated with secondary antibody for $1 \mathrm{hr}$ at room temperature. Slides were washed and immediately treated with DAB chromogen substrate for 5 mins, then counterstained in Hematoxyline, and rinsed in deionized water. Slides were then rehydrated in alcohol and Xylene, dried, and mounted on a DPX mounting medium then examined under a light microscope to evaluate the severity of gene expressions.

CD4+, CD8+, and ICAM-1 immunopositivity were analyzed using Image $\mathrm{J}$ software. Morphometric results were determined as the percentage of specific positive area in relation to the total counted area and expressed as mean \pm SD.

\section{Reverse Transcriptase And Quantification Of Collagen Type-I Gene Expression}

The isolation of total RNA from the skin tissue of different experimental groups $(50 \mathrm{mg})$ was performed according to the manufacturer protocol of the RNeasyR tissue mini kit (Qiagen). Both the quality and amount of the extracted total RNA were checked using a NanoDrop 1000 Spectrophotometer. The cDNA was synthesized using the first-strand cDNA synthesis kit (Fermentas, Life Sciences). The cDNA was then used in the real-time PCR step that was performed using BioEasy SYBR Green I Real-Time PCR Kit. PCR amplification consisted of $45 \mathrm{~s}$ at $94{ }^{\circ} \mathrm{C}, 45 \mathrm{~s}$ at $59^{\circ} \mathrm{C}$, and $45 \mathrm{~s}$ at $72{ }^{\circ} \mathrm{C}$ for 40 cycles. Transcript levels were normalized to those of glyceraldehyde 3-phosphate dehydrogenase $(G A P D H)$ the primer sequence for GAPDH was used 
as reported by Morgan et $\mathrm{al}^{37}$. Collagen type I gene forward and reverse primer were $\mathrm{F}$ AACAAGGGAGGAGAGAGT GC; R AGTCTCTTGCTTCCTCCCAC. PCR specificity was verified by melting curve analysis. All samples were analyzed in duplicate, and relative gene expression was calculated by the $2^{-\Delta \Delta C t}$ method.

\section{Oxidative Stress Evaluations}

The prepared skin tissue homogenates were evaluated for Lipid peroxide content by quantifying the thiobarbituric acid reactive substances (TBARs) level according to the method described by Yoshioka et $a l^{38}$ Determination of reduced glutathione (GSH) content was performed according to Ellman, ${ }^{39}$ as well as Catalase (CAT) activity as the antioxidant enzyme, was assessed according to the method of Aebi ${ }^{40}$ using commercial kits (Biodiagnostics, Cairo, Egypt).

\section{Statistical Analysis}

Statistical analysis was performed utilizing SPSS version 16.0 software (SPSS Inc., Chicago, IL, USA). Data were expressed as means \pm significant difference (SD). Comparison of means was performed by one-way analysis of variance (ANOVA) followed by independent test. A value of $P \leq 0.05$ was considered a statistically significant difference according to the method described by Hassanen et al. $^{41}$

\section{Results}

\section{Characterization Of The Prepared Nanoparticles $X$-Ray Diffraction (XRD)}

A typical powder XRD pattern of a synthesized nanometer-sized zinc oxide powder has been presented in Figure 1A. The XRD of the synthesized zinc oxide showed broad peaks at 2 theta values of $31.77^{\circ}, 34.4^{\circ}, 36.26^{\circ}$, $47.54^{\circ}, 56.60^{\circ}, 62.86^{\circ}, 66.38^{\circ}, 67.95^{\circ}, 69.09^{\circ}, 72.57^{\circ}$, and $76.97^{\circ}$ which were typical for the zinc oxide structure. The peak positions were in good agreement with the JCPDS (5-0664). The main ( $\mathrm{h} \mathrm{k} \mathrm{l)} \mathrm{indices} \mathrm{for} \mathrm{nan-}$ ometer-sized ZnO: ((100), (002), (101), (102), (110), (103), (200), (112), (201), (004), and (202).

\section{High-Resolution Transmission Electron Microscopy (HR-TEM)}

The TEM analysis confirmed the presence of nearly spherical shaped morphology with the diameter between 13 and $23 \mathrm{~nm}$ (Figure 1B).

\section{Gross Pathology Of Dermatitis In Different Groups}

The macroscopic observation of the skin revealed skin inflammation in the group exposed to lead oxide only starting from one week from the initial application. The onset of skin inflammation appeared as mild erythema and edema then the back skin thickened and showed severe erythema, hemorrhage, erosions, ulceration, and crusting formation after two weeks. The dermatitis score reached the maximum levels in all parameters (score $\approx 3$ ) in this group. On the other hand, rats treated with $\mathrm{ZnO}-\mathrm{NPs}$ cream either with low $(1 \%)$ or high $(6 \%)$ concentration ameliorated the skin lesions but, the better improvements observed in low concentration $(1 \%)$ of $\mathrm{ZnO}-\mathrm{NPs}$ (score $\approx 1$ ). The previously observed skin lesions progressively worsened after 2 weeks from the initial treatment. Whereas, rats treated with $6 \%$ $\mathrm{ZnO}-\mathrm{NPs}$ ( score $\approx 2$ ) were showed minute foci of ulceration as well as moderate skin thickening.

\section{Histopathological Examination}

Microscopic examination of skin tissue sections in rats from the control group and groups treated with nano-zinc oxide cream either with low $1 \%$ or high $6 \%$ concentration were the same and revealed normal skin thickness (Figure 2A) with normal histology (Figure 2B and C). On the other hand, skin tissue sections in rats exposed to lead oxide revealed severe sub-chronic allergic dermatitis with a high score in all of the observable lesions as showed in the Table 2. There was epidermal hyperplasia characterized by increasing epidermal thickness associated with acanthosis, parakeratosis, and hyperkeratosis (Figure 2D). Multiple pustules containing neutrophils also observed in the sub-corneal layer in addition to epidermal kerato-acanthosis and keratocysts. Epidermal edema in the form of spongiosis (intercellular edema) and epithelial vacuolar degeneration (intracellular edema) was recorded (Figure 2E). There was thickening in the dermal layer associated with severe congestion, edema, hemorrhage, inflammatory cells infiltration mainly lymphocytes and neutrophils especially at the perivascular area (Figure 2F). There was a remarkable improvement in the skin lesions in rats treated with $\mathrm{ZnO}$ NPs either when applied topically with low or high concentrations. However, the most ameliorative effects recorded in rats treated with $1 \% \mathrm{ZnO}$ NPs. There was a significant decrease in the full skin thickness in all $\mathrm{ZnO}$ NPs treated rats when compared with lead oxide exposed group (Figure $2 \mathrm{G}$ and J). Epidermal layer showing normal histology neither crust nor inflammatory cells 

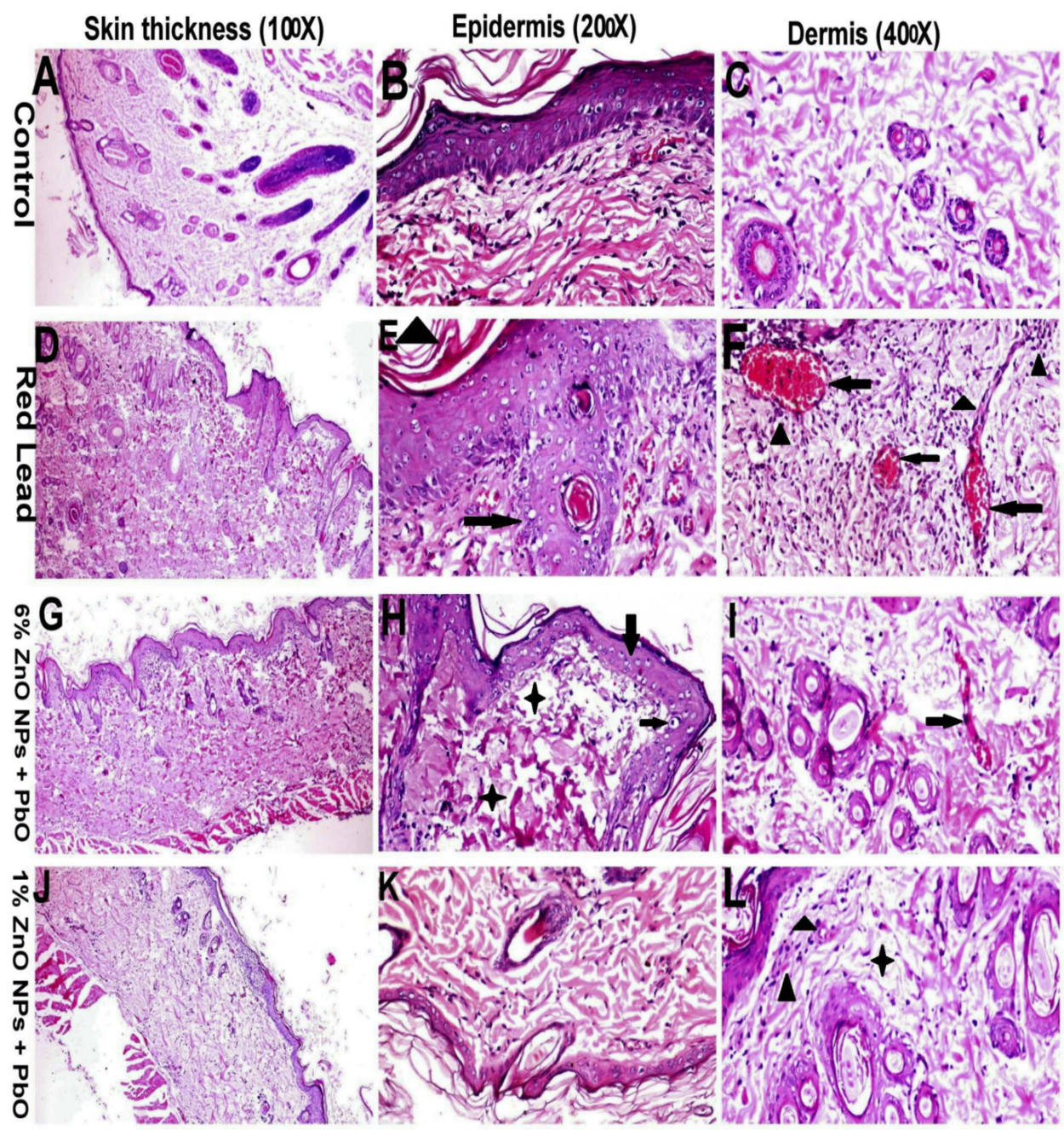

Figure 2 Histopathological alterations in the skin tissue sections of rats in different groups. (A-C) Skin of rats in control groups showing normal epidermal and dermal layers. (D-F) Skin of rats treated with PbO showing, (D) increasing skin layer thickness, (E) epidermal hyperplasia (arrow), vacuolar degenerations, and hyperkeratosis (arrowhead), (F) Severe dermal congestion (arrow), edema and inflammatory cells infiltration especially around blood vessels (arrowhead). (G-I) Skin of rats treated with both $\mathrm{PbO}$ and $6 \% \mathrm{ZnO}$ NPs showing, (G) Normal skin thickness, (H) Epidermal vacuolar degeneration (arrow) with dermal edema (star), (I) Moderate dermal edema with mild congestion (arrow). (J-L) Skin of rats treated with both PbO and I\% ZnO NPs showing, (J) normal skin thickness, (K) normal epidermal and dermal histology, (L) mild dermal edema (star) with minimum inflammatory cells infiltrations (arrow) (H\&E staining for all figs).

Table 2 Scoring Of The Histopathological Lesions In The Skin Tissue Sections

\begin{tabular}{|l|l|l|l|l|l|l|}
\hline & C -ve & I\%ZnO NPs & 6\%ZnO NPs & PbO & PbO+ 6\%ZnONPs & PbO+ I\%ZnONPs \\
\hline Epidermal edema & - & - & + & +++ & + & - \\
Epidermal hyperplasia & - & - & - & +++ & + & - \\
Dermal edema & + & + & + & +++ & ++ & + \\
Dermal inflammation & - & - & + & +++ & + & + \\
\hline
\end{tabular}

Notes: $(-)$ no, $(+)$ mild, $(++)$ moderate, $(+++)$ severe histopathological alterations Abbreviations: $\mathrm{ZnO}-\mathrm{NPs}$, zinc oxide nanoparticles; $\mathrm{PbO}$, lead oxide.

infiltration were observed (Figure $2 \mathrm{~K}$ ) except for those treated with $6 \% \mathrm{ZnO}$ NPs showed minimum vacuolar degeneration in the stratum spongiosis (Figure $2 \mathrm{H}$ ). There was a remarkable reduction in the dermal inflammatory cells infiltrations in rats treated with $1 \% \mathrm{ZnO}$ NPs (Figure $2 \mathrm{~L}$ ) but still present in those treated with $6 \% \mathrm{ZnO}$ NPs and associated with moderate congestion and edema (Figure 2I).

Toluidine blue and Congo red staining were performed to recognize mast cells and eosinophils respectively (Figure 3). The result revealed that the number of toluidine blue positive 
mast cells and Congo red positive eosinophils were increased markedly in lead oxide exposed group. The number of both mast cells and eosinophils also reduced in rats treated with either $1 \%$ or $6 \% \mathrm{ZnO}-\mathrm{NPs}$ Table 3.

\section{Immunohistochemical Studies}

Immunohistochemical staining was performed to analyze different T-cell types and intercellular adhesion molecule-1
(ICAM-1) gene expression in skin tissue sections in different groups (Figure 4 and Table 4 ). The number of $\mathrm{CD}^{+}$and CD8 $+\mathrm{T}$ - lymphocytes were remarkably induced in rats exposed to lead oxide, while reduced in those treated with either $1 \%$ or $6 \% \mathrm{ZnO}-\mathrm{NPs}$. There were also marked ICAM-1 gene expression among dermal leukocytes and endothelial cells lining dermal blood vessels. On the other hand, we observed that ICAM-1 gene expression in the dermal layer decreased
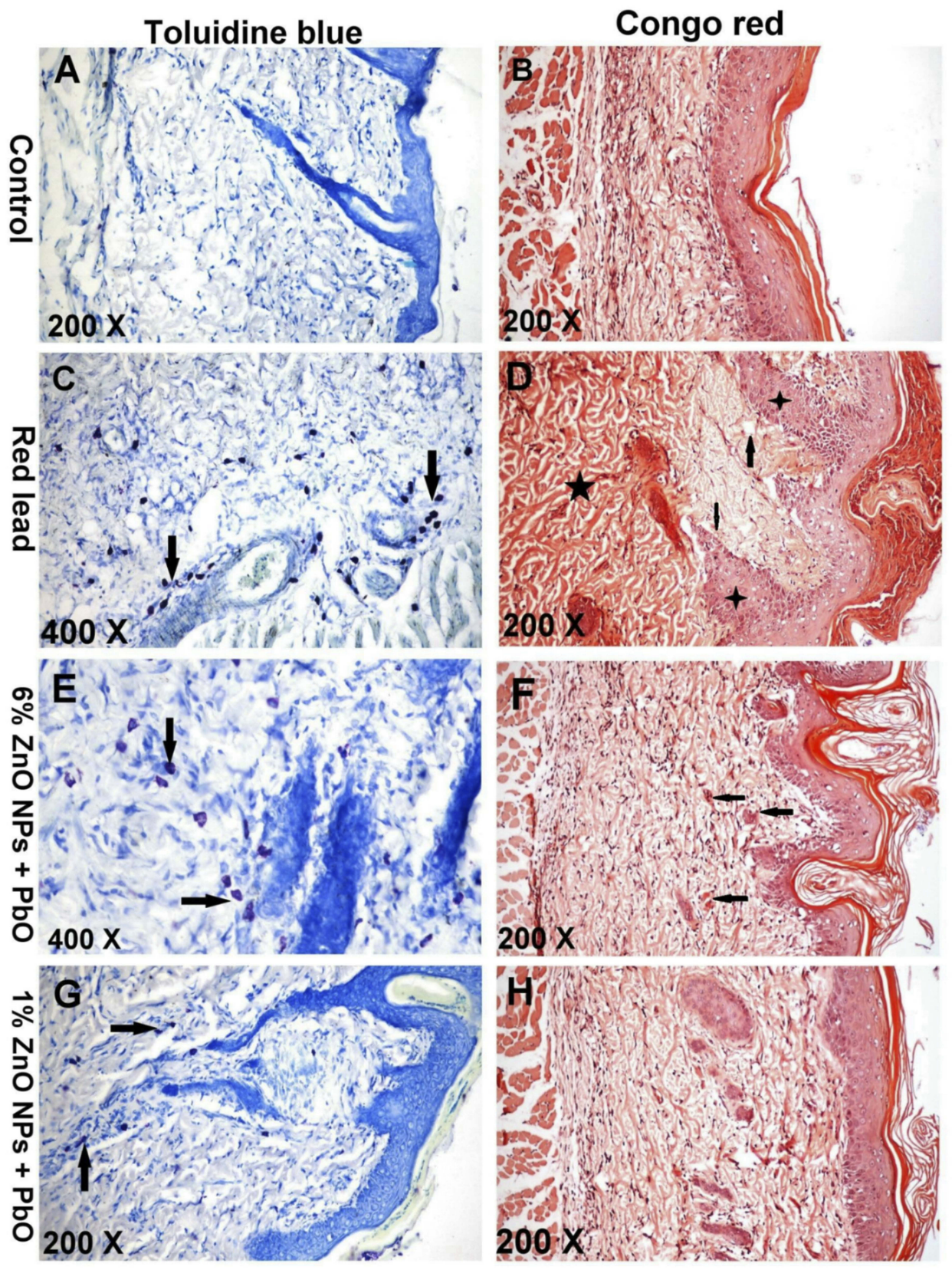

Figure 3 Toluidine blue and Congo red staining of the skin lesions. (A-B) Skin of rats in control groups showing minimum mast cells (arrow) (A) and eosinophils (arrow) (B) in the dermal layer. (C-D) Skin of rats treated with $\mathrm{PbO}$ showing, (C) marked mast cells infiltrations (arrow) in the dermis especially around dermal blood vessels. (D) minimum dermal eosinophils (arrow) with marked dermal eosinophilia (star), note: epidermal hyperplasia. (E-F) skin of rats treated with both PbO and 6\% ZnO NPs show, (E) A moderate amount of mast cells (arrow) in the dermis. (F) the minimum amount of eosinophils (arrow) in the dermis. (G-H) skin of rats treated with both PbO and I\% $\mathrm{ZnO}$ NPs showing minimum mast cells (arrow) $(\mathbf{G})$ and eosinophils (arrow) $\mathbf{( H )}$ in the dermal layer. 
Table 3 Morphometric Studies Of The Histopathological Lesions Of The Skin Sections In Different Groups

\begin{tabular}{|l|l|l|l|l|l|l|}
\hline & C -ve & I\%ZnO NPs & 6\%ZnO NPs & PbO & PbO+ 6\%ZnONPs & PbO+ I\%ZnONPs \\
\hline Mean skin thickness (um) & $260 \pm 5$ & $279 \pm 3.5$ & $290 \pm 5$ & $590 \pm 6.5^{*}$ & $345 \pm 3.5^{*}$ & $275 \pm 4$ \\
TB+ cells (cells/field) & $5 \pm 1.2$ & $8 \pm 0.3$ & $5 \pm 0.1$ & $49 \pm 2.5^{*}$ & $25 \pm 3^{*}$ & $7 \pm 1.5$ \\
CR+ cells (cells/field) & $5 \pm I$ & $8 \pm 1.3$ & $8 \pm 0.5$ & $55 \pm 3.5^{*}$ & $20 \pm I^{*}$ & $8 \pm 1.5$ \\
\hline
\end{tabular}

Notes: Values are presented as mean $\pm S D$, ${ }^{*}$ means a significant difference from the control group at $P \leq 0.05$.

Abbreviations: TB, Toluidine blue stain; CR, Congo red stain; ZnO-NPs, zinc oxide nanoparticles, PbO: lead oxide.

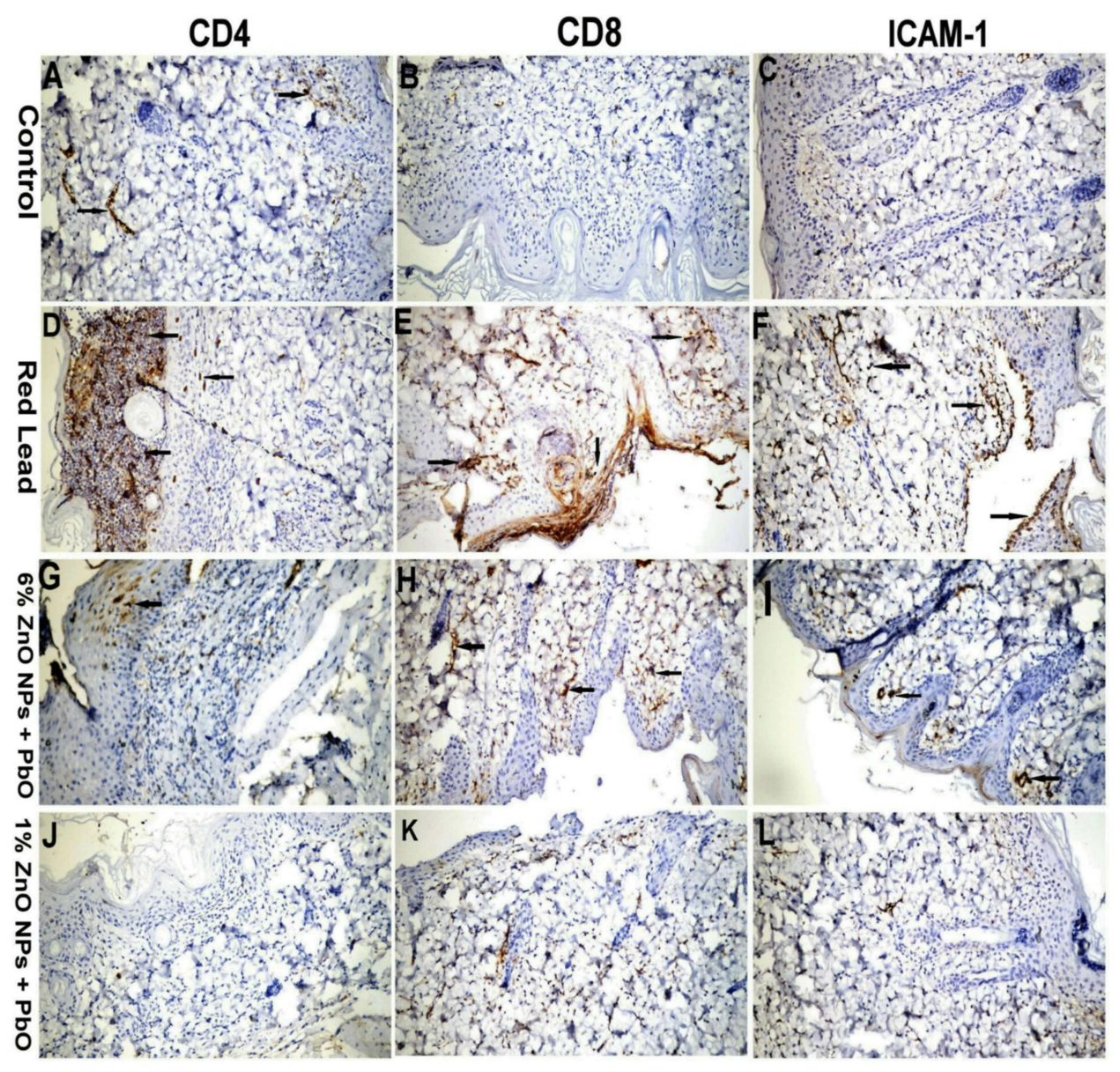

Figure 4 Immunohistochemical staining of the skin tissue sections showing mild to negative CD4, CD8 and ICAM-I gene expression among the skin tissues in control groups (A, B, C). A marked increase in a number of cells expressed CD4, CD8 and ICAM-I among dermal and epidermal layers observed in the group received lead oxide (D, E, F). Moderate reactions of the above gene expression among the skin tissue sections in $6 \% \mathrm{ZnO}$ NPs pretreated rats (G, H, I). Mild to negative gene expression among the skin tissues in I\%ZnO NPs pretreated rats (J, K, L) (IHC X200 for all figs).

dramatically after treatment of rats by $1 \%$ nano-zinc oxide cream and still high, but not significant, in rats treated with $6 \%$ nanosized zinc oxide cream.

\section{Reverse Transcriptase (RT) And Quantification Of Collagen Type I Gene Expression}

The effect of lead oxide and zinc oxide nanoparticles on collagen gene expression level in the skin was demonstrated in Figure 5A. According to the present study, lead oxide-exposed rats up-regulate the expression level of the collagen gene compared to the control group by more than 3 folds. Different doses of nano zinc-induced significant down-regulation of collagen expression in skin tissue by $78 \%$ in $6 \%$ nano zinc and $82 \%$ in $1 \%$ nano zinc compared to lead oxide intoxicated group. Co-administration of nano zinc oxide cream reduced the up-regulation of the expression of the collagen gene as compared to lead 
Table 4 Mean \%area Of The Immunopositivity Of Different Immunohistochemical Markers In Different Groups

\begin{tabular}{|l|l|l|l|l|}
\hline & Control & PbO & $\begin{array}{l}\text { PbO+ 6\%ZnO } \\
\text { NPs }\end{array}$ & $\begin{array}{l}\text { PbO+ I\%ZnO } \\
\text { NPs }\end{array}$ \\
\hline CD4 & $5 \pm 0.3$ & $25 \pm 1.5^{*}$ & $5 \pm 1 . I$ & $7 \pm 2.5$ \\
CD8 & $I \pm 0.0$ & $45 \pm 2.2^{*}$ & $15 \pm 0.5$ & $8 \pm 2.6$ \\
ICAM-I & $I \pm 0.0$ & $30 \pm 1.3^{*}$ & $20 \pm 0.7^{*}$ & $5 \pm 3.5$ \\
\hline
\end{tabular}

Notes: Values are presented as mean $\pm \mathrm{SD},{ }^{*}$ means a significant difference from control negative groups at $P \leq 0.05$.

Abbreviations: $C D$, cluster of differentiation; ICAM-I, intercellular adhesion molicules-I; ZnO-NPs, zinc oxide nanoparticles, $\mathrm{PbO}$ : lead oxide.

oxide exposed rats indicating the beneficial effect nano zinc oxide cream against lead dermal toxicity.

\section{Oxidative Stress Evaluations}

Skin oxidative and antioxidative parameters in different groups were summarized in fig (5B, C\&D). Significant lower values concerning catalase activity and reduced glutathione level in addition to significantly higher values of MDA level were observed in the lead-exposed group. The topical application of nano- $\mathrm{ZnO}$ cream either $1 \%$ or $6 \%$ showed nearly similar values of the previous parameters compared to the control group. The application of the protector $\mathrm{ZnO}-\mathrm{NPs}$ cream $1 \%$ and $6 \%$ before lead exposure significantly increased catalase activity and glutathione level when compared with the lead-exposed group and significantly reduced the level of MDA.

\section{Discussion}

Several studies report both in-vivo and in-vitro skin penetration of lead salts and confirmed that $\mathrm{Pb}$ concentrated in the stratum corneum of the skin but absorbed to the blood with low levels and maybe aggregated to other organs. ${ }^{42}$ Although, lead absorption via dermal route is still clear until now but may cause several hazards especially for paint workers. Our results reported that CAT activity and GSH contents lowered in lead oxide exposed rats, while the MDA level extensively increased. Many mechanisms explained this finding including the generation of ROS, reducing the antioxidant defense system of cells via depleting glutathione, interfering with some essential metal, inhibiting sulfhydryl dependent enzymes or antioxidant enzymes activities or increasing susceptibility of cells to oxidative attack by altering membrane integrity and fatty acid composition. ${ }^{43}$ Vaziri et al, ${ }^{44}$ reported that lead has an inhibitory effect on CAT activity which is one of the antioxidant enzymes involved in the prevention of lipid peroxidation. Schwartz et al ${ }^{45}$ founded a decrease in

\section{B MDA (nmol/g tissue)}

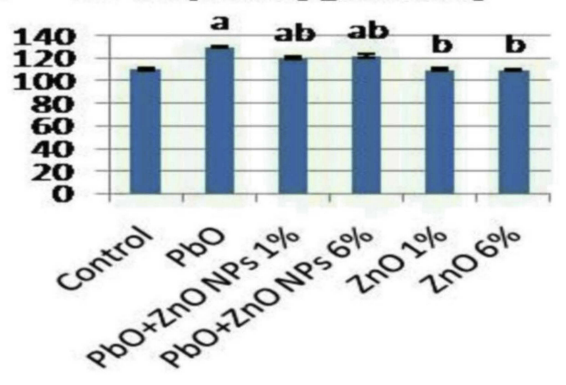

D GSH (mg/E tissue)

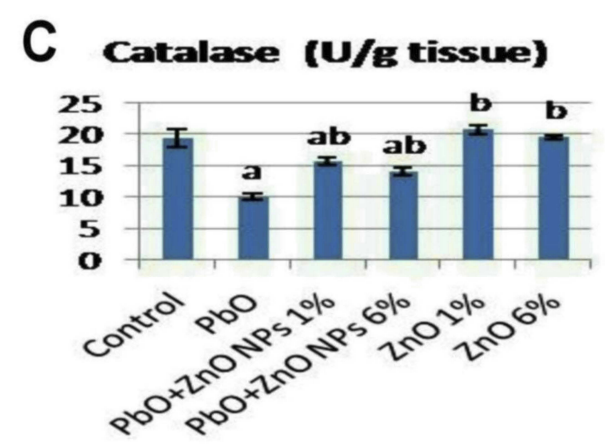

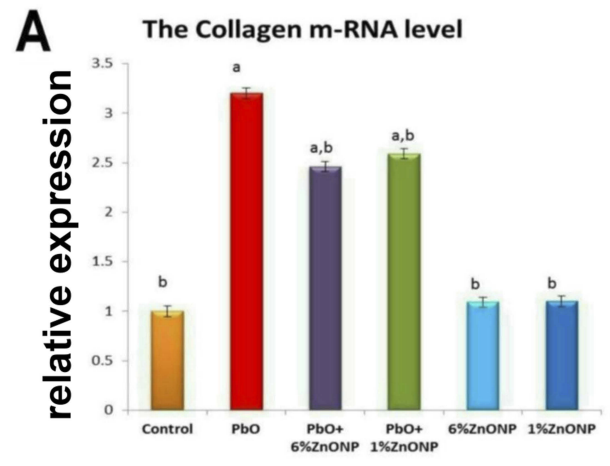

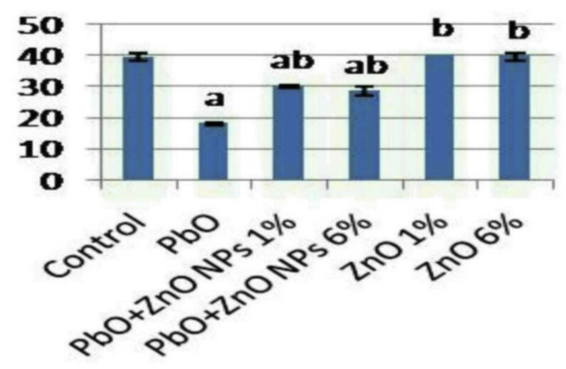

Figure 5 Relative mRNA gene expression of collagen type I (A), serum levels of MDA (B), CAT (C), and GSH (D) in the skin of rats in different experimental groups. Notes: Values are presented as mean $\pm S D$, a: Significant from the control group at $\mathrm{P} \leq 0.05$, b: Significant from $\mathrm{PbO}$ group at $\mathrm{P} \leq 0.05$.

Abbreviations: ZnO-NPs, zinc oxide nanoparticles, $\mathrm{PbO}$, lead oxide, MDA, malondialdehyde, CAT, catalase, GSH, reduced glutathione. 
GSH and an increase in oxidized glutathione (GSSH) concentration in lead treated rats. In agreement with our results, it was observed that a level of total glutathione was significantly reduced while MDA level (lipid peroxidation biomarker) was significantly elevated in lead-exposed rats. $^{46}$

Macroscopic and microscopic examinations were performed in the skin tissue sections and revealed that the topical application of red lead (lead oxide) to the skin of rats for 14 days leading to severe allergic dermatitis manifested macroscopically by skin swelling, redness, and ulcerations. The gross lesions examined microscopically and showing severe epidermal hyperplasia accompanied by vacuolization, dermal edema, and inflammatory cells infiltrations especially mast cells and lymphocytes. Our results are in agreement with several studies which confirmed that lead oxide considered as one of the most systemic toxicants that are known to induce skin and multiple organ damage, even at lower levels of exposure. ${ }^{63,64}$ Histopathological lesions observed in rats received lead oxide may be related to oxidative damage induced by local administration of lead oxide to the skin as discussed previously.

Our study revealed an increase in the number of toluidine blue positive mast cells with a marked increase in Congo red positive eosinophils in the epidermal and dermal layers of the skin of rats administered lead oxide. Traditionally, allergic dermatitis is connected with the presence of mast cells and anaphylactic response. Mast cells are a key factor in the inflammatory and allergic cascade during the course of allergic dermatitis. ${ }^{47}$ Several studies demonstrated that eosinophils also play a major role in the pathogenesis of allergic dermatitis. ${ }^{48}$ Apart from mast cells and eosinophils, other components of the skin immune system such as T cells play an important role in the course of allergic dermatitis. ${ }^{49,50} \mathrm{CD} 4$ is expressed in T-helper cells and is found in approximately $80 \%$ of thymocytes and in $45 \%$ of peripheral blood lymphocytes. ${ }^{51,52} \mathrm{CD} 8$ has been shown to be an important marker in the analysis of T-cell mediated inflammatory dermatoses. CD8 can be used in panels with CD4 to aid in identifying subsets of inflammatory skin diseases. ${ }^{53}$ Although allergic dermatitis has classically been considered a disease induced by $\mathrm{Th} 2 \mathrm{CD} 4^{+} \mathrm{T}$ cells, more recent findings have suggested a pathogenic role for $\mathrm{CD}^{+}$ T cells. ${ }^{54,55}$ In acute and subacute lesions of allergic dermatitis, there is a significant increase in the number of cells expressing CD4 and CD8 in dermis and epidermis. ${ }^{56,57}$ Those mentioned our findings that the numbers of $\mathrm{CD}^{+}$and $\mathrm{CD} 8+\mathrm{T}$ - lymphocytes were remarkably induced in rats exposed to lead oxide.

The present study demonstrates that lead oxide-induced up-regulation of collagen type I gene expression on the skin tissue. Type I collagen is a major extracellular matrix component in the dermis. It is believed that transforming growth factor- $\beta 1$ (TGF- $\beta 1$ )/Smad pathways play key roles in type I collagen synthesis. An important physiological feature of TGF- $\beta 1$ includes the de-novo synthesis of extracellular matrix proteins and the inhibition of the expression of matrix metalloproteinases (MMPs). ${ }^{58}$ ROS can activate fibrogenic gene expression and TGF- $\beta 1$, which is known to play a major role in the activation of tissue fibrosis. ${ }^{59}$ One of the main mechanisms of toxicity of lead oxide is the induction of oxidative stress. ${ }^{60}$ This could be the main cause for up-regulation of collagen expression induced by lead oxide in the present study.

Zinc is considered as one of the most essential micronutrients required for human and animal health. ${ }^{61}$ Zinc plays a major role in regulating every phase of the wound healing process, ranging from membrane repair, oxidative stress, coagulation, inflammation, and immune defenses, tissue re-epithelialization, angiogenesis, to fibrosis of scar formation. Recent advances in drug investigation with ZnO-NPs technology have received significant attention for the treatment of several skin diseases due to their effective cell penetration, antioxidant and antimicrobial capacity. ${ }^{62}$

In the present study, ZnO-NPs accomplished in reducing the toxic effect of lead oxide on the antioxidant parameters, pathological pictures and collagen gene expression in the skin of rats. Microscopic scoring showed remarkable improvements in all parameters except for mild dermal edema and inflammation which were observed in $\mathrm{ZnO}-\mathrm{NPs}$ treated groups. Apart from $\mathrm{ZnO}-$ NPs treatment, this finding may be related to the skin trauma which may occurred during hair removal at the site of application which in turn may lead to increased dermal blood vessels wall permeability and resulted in mild dermal edema and inflammation in all groups. ${ }^{62}$ The number of both mast cells and eosinophils also reduced in rats treated with either $1 \%$ or $6 \% \mathrm{ZnO}-\mathrm{NPs}$. The results of Immunohistochemistry revealed reduction in the immunopositivity of $\mathrm{CD} 4^{+}$and $\mathrm{CD} 8+\mathrm{T}$ - lymphocytes in rats treated with either $1 \%$ or $6 \% \mathrm{ZnO}-\mathrm{NPs}$. ICAM-1 was down-regulated in rats treated with $1 \%$ $\mathrm{ZnO}-\mathrm{NPs}$, whereas up-regulation was recorded in rats 
treated with $6 \% \mathrm{ZnO}-\mathrm{NPs}$. These observations confirmed the concentration-dependent anti-inflammatory effects of $\mathrm{ZnO}-\mathrm{NPs}$ on the injured skin. High concentration of $\mathrm{ZnO}-$ NPs may be irritant to the skin leading to moderate edema and inflammation manifested by moderate immunopositivity of ICAM-1 gene expression. Our findings coincide with a report that evaluated the safety of $\mathrm{ZnO}-\mathrm{NPs}$ on the injured skin and showed that the high concentration of $\mathrm{ZnO}-\mathrm{NPs}$ (more than 10\%) led to dermal toxicity and irritation. ${ }^{63}$ Another study showed that the high concentration of $\mathrm{ZnO}(6 \%)$ had no effect on the process of healing but increased the inflammation in the granulation tissue compared with low concentration (1\%). ${ }^{64}$ The best pathological pictures observed in rats treated with $1 \% \mathrm{ZnO}-\mathrm{NPs}$. According to the present data $\mathrm{ZnO}-\mathrm{NPs}$ induced downregulation of collagen type $\mathrm{I}$ in the skin tissue. Our results revealed the protective role of $\mathrm{ZnO}-\mathrm{NPs}$ cream either at low $(1 \%)$ or high $(6 \%)$ concentrations against skin allergic dermatitis and oxidative damage induced by lead oxide. This may be related to the anti-inflammatory and antioxidant properties of $\mathrm{ZnO}-\mathrm{NPs} .{ }^{65}$ The other mechanism may be the increased $\mathrm{Zn}$ concentration produced from the dissociation of $\mathrm{ZnO}-\mathrm{NPs}$. It is well known that $\mathrm{Zn}$ is a powerful antioxidant metal; it is the core constituent of antioxidant enzymes such as SOD and is cognized protector of sulfhydryl groups; it is also thought to impair lipid peroxidation by displacing transition metals such as iron and copper from catalytic sites. ${ }^{66}$ It was reported that topical application of 3\% zinc sulfate ( $\mathrm{ZnSo} 4)$ has widely used in wound healing due to its antioxidant property. ${ }^{67}$ Also, $\mathrm{ZnO}$ increases collagen degradation in necrotic wounds. ${ }^{68}$ It has been reported that topical application of $\mathrm{ZnO}$ induces mRNA expression of metallothionein, which could account for its anti u photoprotective effect. ${ }^{69}$ It was reported that $\mathrm{ZnO}-\mathrm{NPs}$ are able to protect cell membrane integrity against oxidative stress damage, increase antioxidant enzyme levels, decrease MDA and free radicals levels. $^{70}$

\section{Conclusion}

The frequent exposure of the skin to lead oxide for 14 days caused extensive oxidative stress damage and allergic dermatitis. However, the daily topical application of $\mathrm{ZnO}-\mathrm{NPs}$ either at $1 \%$ or $6 \%$ concentrations alleviated the lead oxide-induced dermal toxicity due to their antioxidant and anti-inflammatory effects. Moreover, the $1 \% \mathrm{ZnO}-$ NPs surpassed the $6 \% \mathrm{ZnO}-\mathrm{NPs}$. Thus, the current findings suggest that $1 \% \mathrm{ZnO}-\mathrm{NPs}$ cream is safe when repeatedly applied on the injured or inflamed skin and may be used daily to prevent dermal toxicity initiated by lead oxide-containing materials and is recommended for paint workers.

\section{Recommendation}

Further studies needed to determine dermal uptake of both lead oxide and $\mathrm{ZnO}-\mathrm{NPs}$ if applied topically on the skin to give more information about their absorption, distribution, and excretion. Bioaccumulation of $\mathrm{ZnO}-\mathrm{NPs}$ in different organs and either their toxic or beneficial effect is very important prior to apply it topically on the inflamed skin to determine their safety.

\section{Disclosure}

The authors report no conflicts of interest in this work.

\section{References}

1. Patra RC, Rautray AK, Swarup D. Oxidative stress in lead and cadmium toxicity and its amelioration. J Vet Intern Med. 2011; 2011:457327.

2. Khalaf AA, Moselhy WA, Abdel-Hamed MI. The protective effect of green tea extract on lead induced oxidative and DNA damage on rat brain. Neurotoxicology. 2012;33(3):280-289. doi:10.1016/j.neuro.2012.02.003

3. Jadhav SH, Sarkar SN, Patil RD, Tripathi HC. Effects of subchronic exposure via drinking water to a mixture of eight water contaminating metals: abiochemical and histopathological study in male rats. Arch Environ Con Toxicol. 2007;53(4):667-677. doi:10.1007/s00244007-0031-0

4. Deborah Blum. Looney gas and lead poisoning: a short, sad history. Wired. 2013 Jan 5, Archived from the original on March 21, 2017.

5. Kington $T$. The mystery of Caravaggio's death solved at last painting killed him. The Guardian. 2010, Archived from the original on August 08, 2013.

6. Flora SJ. Arsenic-induced oxidative stress and its reversibility. Free Radic Biol Med.2011;51(2):257-281. doi:10.1016/j.freeradbiomed.2011.04.011

7. Ishikawa ET, Gonzalez-Nieto D, Ghiaur G, et al. Connexin-43 prevents hematopoietic stem cell senescence through transfer of reactive oxygen species to bone marrow stromal cells. Proc Natl Acad Sci. 2012;109(23):9071-9076. doi:10.1073/pnas.1120358109

8. Flora SJ, Mittal M, Mehta A. Heavy metal induced oxidative stress \& its possible reversal by chelation therapy. Indian $J$ Med Res. 2008;128(4):501-523.

9. Timbrell JA, editor. Biochemical mechanisms of toxicity: specific examples. In: Principles of Biochemical Toxicology. 4th edition. Boca Raton: Informa Health Care; 2008.

10. Needleman H. Lead poisoning. Annu Rev Med. 2004;55:209-222. doi:10.1146/annurev.med.55.091902.103653

11. Vollmer DL, West VA, Lephart ED. Enhancing skin health: by oral administration of natural compounds and minerals with implications to the dermal microbiome. Int J Mol Sci. 2018;19(10):3059. doi:10.3390/ijms19103059

12. Cen L, Liu W, Cui L, Zhang W, Cao Y. Collagen tissue engineering: development of novel biomaterials and applications. Pediat Res. 2008;63:492-496. doi:10.1203/PDR.0b013e31816c5bc3

13. Amini Z, Mahdavi-Shahri N, Lari R, Rassouli FB. The effects of lead on the development of somites in chick embryos (Gallus gallusdomesticus) under in vitro conditions: a histological study. Toxicol Res (Camb). 2019. doi:10.1039/C8TX00340H 
14. Baki MT, Yildizgoren MK, Ekiz T, Tutkun E, Ozcakar L. Ultrasonographic measurement of the achilles and supraspinatus tendon thicknesses in patients with chronic lead exposure. West Indian Med J. 2015;64:384-387.

15. Yuan LG, Yin Z, Dai S, et al. Effects of subchronic exposure to lead acetate and cadmium chloride on rat's bone: ca and Pi contents, bone density, and histopathological evaluation. Int J Clin Exp Pathol. 2014;7:640-647. 44.

16. Akhavan A, Cohen SR. The relationship between atopic dermatitis and contact dermatitis. ClinDermatol. 2003;21:158-162.

17. Kondo S, Sauder DN. Epidermal cytokines in allergic contact dermatitis. J Am Acad Dermatol. 1995;33:786-800. doi:10.1016/0190-9622 (95)91817-5

18. Piguet PF, Garu GE, Hauser C, Vassalli P. Tumor necrosis factor is a critical mediator in hapten-induced irritant and contact hypersensitivity reactions. J Exp Med. 1991;173:673-679. doi:10.1084/jem.173.3.673

19. Maguire HC Jr. Murine recombinant IL-12 increases the acquisition of allergic contact dermatitis in the mouse. Int Arch Allergy Immunol. 1995;106:166-168. doi:10.1159/000236839

20. Charman C, Morris AD, Williams HC. Topical corticosteroid phobia in patients with atopic dermatitis. Br J Dermatol. 2000;142:931-936. doi:10.1046/j.1365-2133.2000.03473.x

21. Abma EM, Blanken R, DeHeide LJ. Cushing syndrome caused by topical steroid therapy for psoriasis. Neth J Med. 2002;60:148-150.

22. Retamo S, Remitz A, Kyllchen H, et al. Topical corticosteroid immunomodulation in the treatment of atopic dermatitis. Am J Clin Dermatol. 2002;3:381-388.

23. Werfel T. The role of leukocytes, keratinocytes, and allergen-specific $\mathrm{IgE}$ in the development of atopic dermatitis. J Invest Dermatol. 2009;129:1878-1891. doi:10.1038/jid.2009.71

24. Bieber T. Atopic dermatitis. Ann Dermatol. 2010;22:125-137. doi:10. 5021/ad.2010.22.2.125

25. Fonacier LS, Dreskin SC, Leung DY. Allergic skin diseases. J Allergy Clin Immunol. 2010;125:S138-S149. doi:10.1016/j.jaci.2009.05.039

26. Wiechers JW, Musee N. Engineered inorganic nanoparticles and cosmetics: facts, issues, knowledge gaps and challenges. J Biomed Nanotechnol. 2010;6:408-431. doi:10.1166/jbn.2010.1143

27. Jones N, Ray B, Ranjit KT, Manna AC. Antibacterial activity of ZnO nanoparticle suspensions on a broad spectrum of microorganisms. FEMS Microbiol Lett. 2008;279:71-76. doi:10.1111/j.1574-6968.2007.01012.x

28. Wang SQ, Tooley IR. Photoprotection in the era of nanotechnology. SeminCutan Med Surg. 2011;30:210-213.

29. Wang SQ, Balagula Y, Osterwalder U. Photoprotection: a review of the current and future technologies. DermatolTher. 2010;23:31-47.

30. Landsiedel R, Ma-Hock L, Kroll A, et al. Testing metal-oxide nanomaterials for human safety. Adv Mater. 2010;22:2601-2627. doi:10.1002/adma.v22:24

31. Kumar SS, Venkateswarlu P, Rao VR, Rao GN. Synthesis, characterization and optical propertiesof zinc oxide nanoparticles. International. Nano Lett. 2013;3(30):1-6.

32. Ugandar RE, Sakthy Deivi K. Formulation and evaluation of natural palm oil based vanishing cream. Ijpsr. 2013;4(9):3375-3380.

33. Ågren MS, Lennart Franzén MD, Milos Chvapil MD. Effects on wound healing of zinc oxide in a hydrocolloid dressing. J Am Acad Dermatol. 1993;29(2, Part 1):221-227. doi:10.1016/0190-9622(93)70172-p

34. Jeong Y-I, Hong S-H, Cho S-H, Lee W-J, Lee S-E. Toxoplasma gondii infection suppresses house dust mite extract-induced atopic dermatitis in NC/Nga mice. Allergy Asthma Immunol Res. 2015;7 (6):557-564. doi:10.4168/aair.2015.7.6.557

35. Bancroft JD, Gamble M. Theory and Practice of Histological Techniques. 6th ed ed. Philadelphia, PA: Churchill Livingstone/ Elsevier; 2008.

36. Hassanen EI, Khalaf AA, Tohamy AF, Mohammed ER, Farroh KY. Toxicopathological and immunological studies on different concentrations of chitosan-silver nanoparticles in rats. Int $J$ Nanomed. 2019;14:4723-4739. doi:10.2147/IJN.S207644
37. Morgan A, Galal MK, Ogaly HA, Ibrahim MA, R M A-E, Noshy P. Tiron ameliorates oxidative stress and inflammation in titanium dioxide nanoparticles induced nephrotoxicity of male rats. Biomed Pharmacother. 2017;93:779-787. doi:10.1016/j.biopha.2017.07.006

38. Yoshioka T, Kawada K, Shimada T, Mori M. lipid peroxidation in maternal and cord blood and protective mechanism against activatedoxygen toxicity in the blood. Am J Obstet Gynecol. 1979;135:372376. doi:10.1016/0002-9378(79)90708-7

39. Ellman GL. Tissue sulfhydryl groups. Arch Biochem Biophys. 1959;82:70-77. doi:10.1016/0003-9861(59)90090-6

40. Aebi H. Catalase. In: Bergemeyer HV, editor. Methods of Enzymatic Analysis. New York: Public Academic Press; 1974:673-684.

41. Hassanen EI, Azouz RA, Azouz AA. Toxicopathological studies on cisplatin toxicity in rats and trials for protection using green tea extract and coriandrum Sativum L oil. Rjpbcs. 2019; 10(1):393.

42. Filon FL, Boeniger M, Maina G, Adami G, Spinelli P, Damian A. Skin absorption of inorganic lead $(\mathrm{PbO})$ and the effect of skin cleansers. J Occup Environ Med. 2006;48(7):692-699. doi:10.1097/ 01.jom.0000214474.61563.1c

43. Sharma S, Sharma V, Pracheta SSH. Therapeutic potential of hydromethanolic root extract of withaniasomnifera on neurological parameters in swiss albino mice subjected to lead nitrate. Int $J$ Curr Pharmaceu Res. 2011;3:52-56.

44. Vaziri ND, Lin CY, Farmand F, Sindhu RK. Superoxide dismutase, catalase, glutathione peroxidase and NADPH oxidase in lead induced hypertension. Kidney Int. 2003;63:186-194. doi:10.1046/j.15231755.2003.00711.x

45. Schwartz BS, Lee BK, Lee GS. Associations of blood lead, dimercaptosuccinic acid chelatable. Lead and tibia lead with polymorphisms in the vitamin D receptor and $\delta$ - aminolevulinic acid dehydratase genes. Environ Health Perspect. 2000;108:949954.

46. Offor SJ, Mbagwu HOC, Orisakwe OE. Lead induced hepato-renal damage in male albino rats and effects of activated charcoal. Front Pharmacol. 2017. doi:10.3389/fphar.2017.00107

47. Duffus JH. Heavy metals - a meaningless term? Pure Appl Chem. 2002;74:793-807. doi:10.1351/pac200274050793

48. Fergusson JE. The Heavy Elements: Chemistry, Environmental Impact and Health Effects. Oxford: Pergamon; 1990.

49. Hodak E, David M, Maron L, et al. CD4/CD8 double-negative epidermotropic cutaneous T-cell lymphoma: an immunohistochemical variant of mycosis fungoides. $J$ Am Acad Dermatol. 2006;55 (2):276-284. doi:10.1016/j.jaad.2006.01.020

50. Tirumalae R, Panjwani PK. Origin use of CD4, CD8, and CD1a immunostains in distinguishing mycosis fungoides from its inflammatory mimics: a pilot study. Indian J Dermatol. 2012;57(6):424427. doi:10.4103/0019-5154.103060

51. Harvell JD, Nowfar-Rad M, Sundram U. An immunohistochemical study of CD4, CD8, TIA-1 and CD56 subsets in inflammatory skin disease. J CutanPathol. 2003;30(2):108-113.

52. Hennino A, Vocanson M, Toussaint Y, et al. Skin-infiltrating CD8+ T cells initiate atopic dermatitis lesions. J Immunol. 2007;178:55715577. doi:10.4049/jimmunol.178.9.5571

53. Hennino A, Jean-Decoster C, Giordano-Labadie F, et al. CD8(+) T cells are recruited early to allergen exposure sites in atopy patch test reactions in human atopic dermatitis. J Allergy Clin Immunol. 2011;127:1064-1067. doi:10.1016/j.jaci.2010.11.022

54. Yamamoto S, Hamasaki Y, Ishii E, Ichimaru T, Miyazaki S. Unbalanced production of interleukin-5 and interleukin-2 in children with atopic dermatitis. Ann Allergy Asthma Immunol. 1997;78:517523. doi:10.1016/S1081-1206(10)63241-3

55. Nakazawa M, Sugi N, Kawaguchi H, et al. Predominance of type cytokines-producing $\mathrm{CD} 4+$ and $\mathrm{CD} 8+$ cells in patients with atopic dermatitis. J Allergy Clin Immunol. 1997;99:673-682. doi:10.1016/ S0091-6749(97)70030-7 
56. Cho J, Il K, Lee K. Downregulation of type I collagen expression in silibinin-treated human skin fibroblasts by blocking the activation of Smad2/3-dependent signaling pathways: potentialtherapeutic use in the chemoprevention of keloids. Int J Mol Med. 2013;31:1148-1152. doi:10.3892/ijmm.2013.1303

57. Sula B, Deveci E, Özevren H, Ekinci C, Elbey B. Immunohistochemical and histopathological changes in the skin of rats after administration of lead acetate. Int $J$ Morphol. 2016;34 (3):918-922. doi:10.4067/S0717-95022016000300017

58. Xiong HM. ZnO nanoparticles applied to bioimaging and drug delivery. Adv Mater. 2013;25:5329-5335. doi:10.1002/adma.2 01301732

59. Oyarzun-Ampuero F, Vidal A, Concha M, Morales J, Orellana S. Moreno-Villoslada I nanoparticles for the treatment of wounds. Curr Pharm Des. 2015;21(29):4329-4341. doi:10.2174/13816128216661 50901104601

60. Abdel Aziz RL, Abdel-Wahab A, Abo El-Ela FI, et al. Dose- dependent ameliorative effects of quercetin and 1-Carnitine against atrazine- induced reproductive toxicity in adult male Albino rats. Biomed Pharmacother. 2018;102:855-864. doi:10.1016/j.biopha.2018.03.136

61. Khalaf AA, Ibrahim AM, Tohamy AF, Allah AAA, Zaki AR. Protective effect of vitazinc on chlorsan induced oxidative stress, genotoxicity and histopathological changes in testicular tissues of male rats. Int J Pharmacol. 2017;13:22-32.

62. Rose BD, Post TW. Chapter 16. In: Clinical Physiology of Acid-Base and Electrolyte Disorders. New York: McGraw-Hill; 2001:961.
63. Ford RA, Api AM, Newberne PM. 90-day dermal toxicity study and neurotoxicity evaluation of nitromusks in the albino rat. Food Chem Toxicol. 1990;28(1):55-61. doi:10.1016/0278-6915(90)90136-b

64. Ågren MS, Lennart Franzén MD. Effects on wound healing of zinc oxide in a hydrocolloid dressing. J Am Acad Dermatol. 1993;29 (2):221-227. doi:10.1016/0190-9622(93)70172-P

65. Afifi M, Abdelazim AM. Ameliorative effect of zinc oxide and silver nanoparticles on antioxidant system in the brain of diabetic rats. Asian Pac J Trop Biomed. 2015;5(10):874-877. doi:10.1016/j.apjtb. 2015.06.010

66. Aitken RJ, Roman SD. Antioxidant systems and oxidative stress in the testes. Oxid Med Cell Longev. 2008;1(1):15-24. doi:10.4161/ oxim.1.1.6843

67. Pinnell SR. Cutaneous photodamage, oxidative stress, and topical antioxidant protection. J Am Acad Dermatol. 2003;48:1-19. doi:10. $1067 / \mathrm{mjd} .2003 .16$

68. Rostan EF, DeBuys HV, Madey DL, Pinnell SR. Evidence supporting zinc as an important antioxidant for skin. Int $J$ Dermatol. 2002;41:606-611. doi:10.1046/j.1365-4362.2002.01567.x

69. Attia EA, Belal DM, El Samahy MH, El Hamamsy MH. A pilot trial using topical regular crystalline insulin vs. aqueous zinc solution for uncomplicated cutaneous wound healing: impact on quality of life. Wound Repair Regen. 2014;22:52-57. doi:10.1111/wrr.12122

70. Dawei AI, Zhisheng W, Angu Z. Protective effects of nano-ZnO on the primary culture mice intestinal epithelial cells in in vitro against oxidative injury. Int J Nanotechnol App. 2009;3:1-6.
International Journal of Nanomedicine

\section{Publish your work in this journal}

The International Journal of Nanomedicine is an international, peerreviewed journal focusing on the application of nanotechnology in diagnostics, therapeutics, and drug delivery systems throughout the biomedical field. This journal is indexed on PubMed Central, MedLine, CAS, SciSearch ${ }^{\circledR}$, Current Contents ${ }^{\mathbb{R}} /$ Clinical Medicine,

\section{Dovepress}

Journal Citation Reports/Science Edition, EMBase, Scopus and the Elsevier Bibliographic databases. The manuscript management system is completely online and includes a very quick and fair peer-review system, which is all easy to use. Visit http://www.dovepress.com/ testimonials.php to read real quotes from published authors. 